\title{
PUS-MODERNIDAD E IRREVERENCIA EN BANDEJA: YOSS Y LA CIENCIA-FICCIÓN EN CUBA EN EL SIGLO XXI
}

\author{
POR \\ Pedro P. PorbéN \\ Bowling Green State University
}

\begin{abstract}
En Cuba... Franz Kafka nunca habría pasado de ser un simple cronista de sucesos ¿Quéun hombre se despertaba convertido en cucaracha? Normal... en La Habana más de una cucaracha se despertaba siendo ministro, o administrador, o gerente. Yoss, Expreso Habana-Amstelven 37
\end{abstract}

"Era el mejor de los tiempos. Era el peor de los tiempos..." Así comienza Expreso Habana-Amstelven (Cuba, 2013)el cuento-novela o cuentinovela más "realista" de ciencia ficción escrito en Cuba. La narradora y protagonista, Eleanor O'Farrill, se mira "“...] al espejo cagado de moscas [y se ve] larga, blanca y rubia con el pelo lacio y los ojos verdes", lacrimosa, soñando con despertarse un día "tan negra y pasúa, con un nombre tan lleno de "Ys" y un apellido tan normal como el de las mellizas Yamirys y Yamarys Echevarría, que se pasaban la vida burlándose de mí, diciéndome "muñequita Barbie"; "jirafita"; "galleta de sal cruda" y otras lindezas por el estilo". Unas páginas más, y se nos aclara que no será ésta una novela, donde se trasplante un cerebro humano al cuerpo de un elefante como en "el clásico Hoity-Toity de Alexander Beliáev" (12); sino que los cubanos, sin saber cómo, serán trasplantados a países distantes, misteriosamente, siempre a las doce de la media noche, como Cenicientas tropicales.

A partir de aquí, raza, género y sexualidad, (de)construcción de la nación, emigración pos-nacional y globalización, confluyen críticamente en esta novela "pusmoderna" o pos-revolución que fue un cuento, un híbrido cuento-novela, escrito por José Miguel Sánchez Gómez (Yoss) y publicado recientemente por la editorial cubana Isliada.

Era "el mejor de los tiempos" porque el siglo recién estrenado cumplía una década, y porque "[...] fuese o no verdad, al menos parecía que al fin había quedado definitivamente atrás aquella larga posguerra sin contienda que eufemísticamente se dio en llamar Período Especial" (Expreso 1). En las calles ya no se hablaba de crisis ni carencias, porque los cubanos " $[\ldots]$ consideraban terminada la dura etapa de simplemente sobrevivir, y salían a las calles, olvidando las penurias, para redescubrir la olvidada sonrisa, para vivir" (2). 
Incluso "[...] los gays disfrutaban la nueva tolerancia que les había abierto las puertas [...]" nos cuenta Eleanor O'Farrill, quienes se reunían "[...] en la zona gay: Chernobil, Cayo Pluma o 23 y Malecón, como cada uno quiera llamarla" (10). La apertura interna y la tolerancia atraía entonces "mandas" de turistas "ansiosos de sumarse a la gran fiesta derrochadora de ingenio y simpatía que era una vez más La Habana" (3).

Pero era, a la misma vez, "el peor de los tiempos" porque los cubanos "[...] todos salían a las calles, con una sonrisa sintética cosida al rostro, a buscar la moneda dura de una u otra manera... era un tiempo de milagros y catástrofes, un tiempo de ángeles y monstruos" (3). Después de leer unas pocas líneas, decidí comprar un ejemplar del cuento-novela en el aeropuerto de La Habana, de regreso a los Estados Unidos después de una visita académico-familiar -ya sabemos que la necesidad es la madre de las invenciones-. Mientras esperaba en la cola, hojeando, cruzo una frase, o la frase cruza mi visión periférica, que desmonta inmediatamente mi sistema: "[...] vivimos prisioneros de la lógica artificial de causa-efecto que nos hemos creado nosotros mismos" (10). Estoy rodeado de bisutería oficial y barata, de tabacos Habanos y rones que no podré llevar conmigo aunque el letrero a la entrada reza "Duty Free". En mi solitario ejemplar del libro, Yoss advertía en la contraportada de la cuentinovela que ALGO había pasado en La Habana del nuevo siglo: "algo" no alcanzaba a describir la idea de que yo estaba leyendo rodeado de guardias aduanales y policías un cuento de Yoss que nos describía como "prisioneros" en un panóptico insular auto-monitoreado. Pero había más: “[...] los colores en el cielo, la claridad como si fuera de día, el efecto estroboscópico como en una discoteca gigantesca". ¿Cómo no comprar un libro que promete convertir a la ciudad capital en una enorme discoteca? Es como si de pronto todos mis años juveniles intentando colarme en las disco de moda habaneras, aquellas que solamente eran/son para extranjeros o gente con chavos, se vieran vindicados porque ALGO estaba ocurriendo, ¿la democratización final del entretenimiento nocturno en el panóptico tropical? Y a continuación se aclaraba, que "[...] circunstancias inauditas típicas del género de la ciencia ficción" serían mezcladas con una investigación policiaca que dilucidaría "[...] la causa de extrañas apariciones de cubanos en los más disímiles lugares del planeta". ¿Cubanos en lugares disímiles bajo extrañas circunstancias? A quién se le ocurre semejante novela... iMe cobra por favor!

Con una versión complaciente de esa "sonrisa sintética cosida al rostro" a la que se refería el libro que estaba a punto de comprar, la dependienta me explicó que ella no sabía cómo había llegado ese libro a la tienda, que tendría que regresar "en un ratico" hasta que el administrador encontrara el precio. Le mostré que en la segunda página se podía leer claramente, aunque escrito a mano y con lápiz, el signo de pesos cubanos y el número diez. "Eso es un error compañero" y se le comenzó a descoser la sonrisa, "aquí solamente vendemos en CUCs" y se llevó mi libro al espacio indeterminado de la investigación inventarial. Y todavía alguien se cuestionaría que seguimos siento "prisioneros de la lógica artificial". 
Al final, me clavaron los 10 CUC, es decir, 250 pesos cubanos; pero bueno, qué hacer cuando todos los cubanos, incluyendo al Estado-gobierno "buscan la moneda dura de una u otro forma" (Expreso) -y yo necesito escribir este ensayo para poder pagar, gracias al salario de profesor que no es mucho, el viaje de regreso a la isla para ver a mi familia.

\section{Muerta la CienCia Ficción, ¿LARGa vida AL Realismo Socialista?}

Como ocurre casi siempre con las cosas que nos gustan demasiado, devoré el libro mientras esperaba el avión. Fui al baño, pagué los diez centavos por una hojita de papel higiénico, siempre con el libro bajo el brazo, y recordé que en algún sitio, algunos años atrás mientras trabajaba en mi disertación doctoral, había leído algo que afirmaba que la ciencia ficción en Cuba se había convertido en literatura de evasión política debido a la censura impuesta por le revolución en las décadas posteriores al triunfo de 1959. Busqué la cita en cuanto tuve acceso a mis documentos. Aparecía en uno de los tantos libros que sobre Cuba se han escrito en las academias internacionales; la distinción, era que ese volumen editado en el 2007 por Fabry y Canaparo, comparaba la situación política cubana con la de Argentina y México, para resumir toda la ciencia ficción cubana de la siguiente manera: “[...] la ciencia ficción cubana parte ante todo de la situación política de Cuba. La censura la obliga a servirse de un lenguaje metafórico y la convierte en literatura de "evasión política"' (179). Especialmente después de terminar de leer Expreso Habana-Amstelven la afirmación, que aparece repetida en no pocos ensayos sobre el tema, me resultó como mínimo simplista y maniquea; de ser cierta, ¿para qué me gasté casi veinte dólares en este libro? Y es que la censura cultural en Cuba y la consecuente muerte de la creación del género fantástico, y el silencio editorial en torno a la ciencia ficción en particular, ha sido bien argumentada durante las últimas cinco décadas. ${ }^{1}$ Por ejemplo, el mismo Yoss recoge en otro texto suyo las experiencias de varias generaciones con respecto a la censura, y aquella etapa culturalmente tan "obscura" que se ha llamado "quinquenio gris", de la siguiente manera: "[...] el quinquenio gris (que para algunos duró un decenio o más), etapa de triste y obscura mediocridad dentro de la literatura cubana. En los afanes de purificación ideológica bajo la sombra del lema (bastante extremista e impreciso, como tantas buenas consignas) dentro de la Revolución todo, contra la Revolución nada [...]" (Yoss, "Marcianos en el platanal” 20; énfasis mías).

Ese complejo y escurridizo período, “decenio gris” para algunos críticos, también considerado como el "quinquenio gris" o "época de silencio," se puede trazar si bien inconsistentemente desde finales de la década de 1960 a finales de la próxima, y estuvo signado por “el 'silencio' editorial de la ciencia ficción escrita en Cuba y por autores

\footnotetext{
Para una discusión sobre el tema ver: Guanche y López Sacha.
} 
del patio" (Román 65-69). Si bien fueron aquellos tiempos en que el policíaco cubano desplazó a la ciencia ficción, realmente fue un período marcado más por la influencia de textos extranjeros, sobre todo soviéticos, aunque realmente también se publican en español escritores ingleses, francés y norteamericanos, y sobre todo por la imposición de un molde del realismo socialista a lo cubano que permitiera al pueblo "sentirse protagonista" de la nueva sociedad y "artífice del procesos revolucionario" que había comenzado en 1959 (González 2). No obstante, debemos recordar que la ciencia ficción cubana, como género, era casi inexistente antes del triunfo revolucionario. Circulaba sobre todo entonces el Pulp Science Fiction norteamericano y pocas revistas, quizás Carteles fue la única, publicaban ciencia ficción de autores cubanos (Román 213-4). A partir de 1961 con la campaña de alfabetización nacional y la emergencia de un sujeto que he llamado en otros sitio "letrado larval", la ciencia ficción norteamericana comienza a desaparecer debido a la invasión de textos procedentes del ahora extinto Campo Socialista Europeo. Fueron los años en que los cubanos vieron a Yuri Gagarin y la perra Laika explorar las inmensidades del cosmos, y la exploración espacial de Sputnik parecía reafirmar que bajo el Socialismo Real el futuro pertenecía a las masas trabajadoras. No obstante, Efremov compartió anaqueles con Bradbury, H.G. Wells y Julio Verne, pero de autores cubanos: nada (o muy poco). A mediados de los sesenta y con el New Wave llegan los autores cubanos Ángel Arango y Oscar Hurtado a las librerías; éste último, facilitando al lector nacional aquellas "prolongadas series de maravillas sucesivas" a través del costumbrismo, la farsa y la fantasía (Acosta en Román 47).

De pronto la ciencia ficción, hecha en Cuba, comenzaba a ofrecer una posibilidad de re-imaginar la literatura cubana, en tanto abría la puerta a un nuevo género que aportaba códigos y temas "visibles" a un consumidor letrado ávido de textos que dialogasen con sus experiencias cotidianas. Pero a finales de 1969, justo cuando en La Habana nacía Yoos, a nivel editorial la ciencia ficción cubana, que tanto empuje tuvo en esa década, comienza a desaparecer. En efecto, ante "los ojos de los celosos comisarios políticos tropicales" aquella literatura de ciencia ficción y fantasía que se destapó pujante en los sesenta, aparecía como "pesimista, antisocial, heréticamente ajena a los sagrados modelos de realismo socialista importados de la URSS"(Yoss, "Marcianos en el platanal" 12); como resultado, "la ciencia ficción cubana estuvo hibernando hasta 1978" cuando "tímidamente" aparece "en el panorama nacional el tema antes tabú del paleocontacto" (Yoss, "Marcianos en el platanal" 13).

Varios factores influyeron en lo que sería el decenio gris que silenció editorialmente a la ciencia ficción cubana. Las críticas mordaces esgrimidas por varios funcionarios políticos a cargo de la cultura nacional no sólo agredieron a las obras sino a los creadores de ciencia ficción, llegándose a considerar el género como escapista, enajenado o enajenante, e incluso contrarrevolucionario, porque, según los censores, era un género que cargaba aún con "el lastre de la influencia yanqui" (Arango; Reloba). Después del 
"caso Padilla" en 1971, la postura oficial se recrudece contra los intelectuales nacionales y sobre todo contra los autores de ciencia ficción que no aceptaron adoptar el molde del realismo socialista. Y es que la ciencia ficción, al abordar posibles futuros, se convirtió en campo político donde la batalla por el control hegemónico de la cultura cubana se tendría que dirimir.

Al concluir la década de los setentas, y con las destituciones de los censores acérrimos como Luis Pavón, director del Consejo Nacional de Cultura y gestor del "caso Padilla", la censura sobre la ciencia ficción disminuye y entramos en lo que se ha llamado la "Edad de Oro de la Ciencia Ficción", pero pocos de los escritores publicados en los sesenta regresarán a las librerías (Sánchez y Noroña en Javier de la Torre 43).

Fue en aquellos momentos que, para algunos críticos y comentaristas, comienza la narrativa cubana del siglo XXI; sin embargo para otros, como Rafael Grillo esa narrativa recién comienza en esta segunda década del nuevo mileno. Es curioso que el indicador principal para Grillo de tal comienzo no es tanto que los escritores "encumbrados", y cita como ejemplo a Leonardo Padura, se estén desplazando hacia los márgenes de sus zonas de confort, en un desplazamiento que no es "evolutivo" sino más bien un "cambio adaptativo" (García Acosta); ese indicador es el empuje de la no-tan-nueva generación de escritores nacidos a finales de 1960 y principios de los setentas. Es "curioso" porque para soportar su argumento Grillo subraya el caso de Yoss cuando recibió "un importante premio de ciencia-ficción en Barcelona" en el 2011 (García Acosta). Interesante o curioso porque el propio Yoss se ha declarado precisamente como un friqui que escribe ficción, el otrora arquetipo del joven marginal que hubiese sido enviado a la UMAP de haber nacido menos de una década antes. Y ahora, quizás como señal de los cambios en tiempos "pusmodernos", en el 2013, Rafael Grillo, editor de la revista cultural "El Caimán Barbudo", está a cargo de la edición de la cuentinovela Expreso Habana-Amstelven, quizás el ejemplo más corrosivo de una crítica sociopolítica a las instituciones que otrora devaluaron no solamente a la ciencia ficción sino a los creadores mismos.

Y regresando a la cita que catalogaba a la ciencia ficción cubana como "literatura escapista", mi intención en este ensayo es privilegiar un análisis de cómo la ciencia ficción cubana del nuevo siglo no ignora la realidad política específica sino que, y a través de recursos variados, refleja las realidades contemporáneas pero obviamente a través de lentes particulares "[...] one associated with the future, with the potentials of technology, and with the important idea that life does not remain static; what we know today may be entirely different tomorrow" (Pearson, Hollinger y Gordon, 3). Pensemos por ejemplo en "Los pecios y los náufragos", "Al final de la senda" o el cuento-novela "Se alquila un planeta," todos de Yoss donde se mezcla el erotismo, la guerra y el 'space opera' con grandes dosis de "referencias metafóricas a la realidad cotidiana" cubana (Yoss, "Marcianos en el platanal" 21). 
Además, cómo es posible considerar cualquier género homogéneamente y calificarlo simplistamente como una "literatura de evasión"; algo así implica un desconocimiento de los procesos culturales en Cuba contemporánea y de la ciencia ficción misma en la isla. Solamente para introducir mi argumento desde la diversidad que demuestra el género, consideremos una novela estilo "fix-up" o pastiche paródico como "El libro fantástico de Oaj" de Miguel Collazo, en el cual ya se combinaban "escenas de la vida cotidiana en La Habana de la década del 50 con fragmentos de la supuesta narración por un escritor saturniano de la invasión de su planeta a La Tierra" (Yoss, "Marcianos en el platanal" 19). E incluso, aquel libro de Luis Alberto Soto quien se las arregló para producir, según Yoos, un texto al estilo de "la peor novela policíaca socialista... esquema de investigador + pueblo contra delincuente o espía, típico de" (Yoss, "Marcianos en el platanal" 20).

Ahora, si por marcadores de censura y evasión se toma el papel que jugó la ciencia ficción en las primeras décadas de revolución como "literatura" de formación política, el panorama, a simple vista, podría parecerse al resto del "realismo socialista" del cual son ejemplos muchas obras de Manuel Cofiño, la novela de Soto, o los documentales de Santiago Álvarez, e incluso los muñequitos de Elpidio Valdés creados por Juan Padrón; y honestamente, a éstas alturas de la crítica cultural en la academia tanto nacional como internacional, hablar de ciencia ficción como literatura de evasión, resulta como dije, simplista y maniqueo: ¡me puedo imaginar la cara de Yoss cuando le conté esto hace poco vía FaceBook!

De hecho, lo que propongo en este ensayo es exactamente comenzar una línea crítica sobre la ciencia ficción cubana en el siglo XXI no sólo como un género importante, sino central, en las discusiones tanto dentro como fuera la isla, sobre la revolución cubana, sobre el proceso o "ficción conveniente" y formativa que se define como tal, como revolucionario. Aquí me hago eco parcial de lo propuesto recientemente por Grillo en que lo se necesita son "intentos de estudiar a profundidad las propuestas y diferencias de los escritores de las nuevas generaciones en Cuba" pues "falta crítica, y no crítica académica, vuelta hacia el pasado y la tradición, sino hacia lo que ahora mismo se está escribiendo y los nuevos autores" (en García Acosta).

Ciencia Ficción o LA ESCANDALOSA VISIBILIDAD DEL Límite

$\mathrm{Y}$ es a partir precisamente de esta urgencia crítica, con la cual coincido, que he venido estructurando mi ensayo; el cual, y parafraseando a mi coterráneo Dennis Mourdoch, "atará cabos para no perderme en la madeja" que resulta la producción de ciencia ficción en Cuba actualmente. No pretendo explorar toda "la madeja", lo cual es simplemente imposible en pocas páginas, pues como aclara Yoss "la ciencia ficción cubana... no constituye in fenómeno estático" pues tuvo, como hemos visto "sus inicios 
vacilantes, sus momentos oscuros, su censura, sus autores gloria, sus escritores malditos y su renacimientos" (2004).

Mi intención es imbricarme con los discursos que circulan actualmente en Cuba en torno a la ciencia ficción, y discutir crítica - quizás apasionadamente- segmentos de la extensísima vida narrativa del propio Yoss; incluyendo en esta tarea "de todo como en botica", un poco de crítica, un poco de erotismo y muchas guayabas... después de todo, "los cubanos de a pie suelen clasificar a toda la ciencia ficción como “itremenda guayaba!" y no solamente porque "la deliciosa fruta tropical" sea "riquísima en vitamina C" sino porque ésta es la manera popular de referirnos a algo increíble: a una gran mentira, al "tupe inicial" (Yoss 2004). Y es que desde mi punto de vista en la ciencia ficción de Yoss -y me atrevería a hacerlo extensivo a otros escritores como Michel Encinosa, Elaine Villas, Gabriel Gil, David Alfonso, Claudio del Castillo y muchos otros miembros de esa generación de cambio a la cual se refirió Grillo- (con)tiene de todo un poco: cyberpunk, space opera, rock y heavy metal, prolijo barroquismo, fantasía y no solamente la heroica, cinismo descarnado, realismo sucio, sexo y neopop y crítica pusmoderna que no es lo mismo que pos-moderna. ${ }^{2}$

La pusmodernidad, como ese quiste podrido que revienta e inunda fétidamente los viejos cánones literarios, es la que enarbola Yoss; es una crítica precisamente a estos críticos que se dedican, y valga la redundancia, a las criticas de la posmodernidad, provocando que el cuerpo literario y en particular la ciencia ficción supuren no lo nuevo y creativo sino lo insano y degradado de la necesidad, a veces imperiosa, de convertirse, el crítico, en quien tiene la última palabra sobre la crítica misma. Este cuento-novela es la novela de "la post-Revolución, Pus-modernidad pura, irreverencia en bandeja" (Expreso 10). Y aún más, y aquí me apropio de lo que recuerdo que dijo una vez el poeta cubano José Kozer refiriéndose a la literatura cubana en general, la ciencia ficción del siglo XXI en Cuba "ventila mucha basura, se enfrenta a la porquería, desmonta las pirámides de las jerarquías", o como se queja Michel, no Foucault, sino el otro, el cubano friqui personaje de Expreso Habana-Amstelven:

tanto experimentador de pacotilla, siempre los mismos en los jurados, se premian unos a otros por el mérito dudoso de mezclar en sus retortas palabrejas rebuscadas, para ganar concursos con dosis calculadas de extrañamiento y angustia generacional. Angustia ni angustia... qué saben ellos de angustia vacilando con sus DVDs en sus casonas de Nuevo Vedado, angustia la de estar un viernes en el Malecón viendo pasar putas y más putas divinas y tú sin un peso en el bolsillo, no la de querer suicidarse con una katana

\footnotetext{
2 Para críticos como Grillo la posmodernidad se debe entender como "la apatía hacia la búsqueda decidida de la novedad" y por ende lo posmoderno "es sobre todo re-lectura o re-escritura de la tradición mediante la fusión genérica o uso de la parodia o evagación de convenciones genéricas o caminos argumentales" (García Acosta). ¿Es esto de lo que habla Yoos cuando se refiere a "pusmodernidad”? No lo creo.
} 
de samurái ni con una granada de Angola, así, bien original, qué clase de mierda, allá el que se la crea. (Expreso 10)

De cierta manera, la ciencia ficción de este siglo responde y no muy tibiamente a la crítica que hacía también Kozer a una "generación cabizbaja" en un mundo compuesto por "chatarra". Lo que me interesa subrayar pues, es la habilidad de la ciencia ficción cubana de pensar fuera de la reproducción mimética de la realidad contemporánea, pero también su capacidad de, al menos en parte y parafraseando a Michel Foucault, de pensar en voz alta lo que se piensa en silencio: "free thought from what it silently thinks, and so enable it to think differently" (citado en Pearson, Hollinger y Gordon 16).

$\mathrm{O}$ dicho de otro modo, quisiera insistir en que la característica que distingue a la ciencia ficción en cuba en el siglo XXI no es la "evasión política" sino, y como afirmó recientemente el escritor cubano Alberto Garrandés, la "escandalosa visibilidad del límite", un escándalo limítrofe "enfocado en el individuo y no en la novedad tecnológica", algo que quizás animó al género en el siglo XX (Garrandés citado en Mourdoch). $\mathrm{O}$ como dice el propio Yoss, lo que distingue a la CF cubana es "la irreverencia en bandeja", en "la patria del machismo leninismo" (Expreso 12). Pero es una irreverencia que está íntimamente preocupada con cuestiones de la vida diaria, del sobrevivir la cotidianeidad, o como nos la presenta Yoss mismo en su cuento-novela Expreso Habana-Amstelven, una irreverente y crítica mirada a la realidad pos-período especial; una complicada realidad donde todo tiene o se le puede poner un precio: "las mujeres vendían su cuerpo, su simpatía, su hermosura, su juventud y su futuro"; y los hombres ofrecían su virilidad, su sentido del humor, su talento musical, su pasado. La Habana encandilaba a los aventureros foráneos con promesas de un "turismo sexual barato, hospitalidad bed-and-breakfast y cariño tan bien fingido que parecía auténtico" (Expreso 5).

La protagonista de Expreso Habana-Amstelven, Eleanor O'Farrill, “con tal de huirle al barrio", y al cuartucho donde leía cada libro que le caía en las manos, se va insertando entre las ruedas de los mecanismos de control militar hasta llegar a ser, no por voluntad propia sino porque la revolución lo pedía, subteniente e Investigadora Judicial, en "la gloriosa PNR" (Policía Nacional Revolucionaria). "La rubia intelectual con el uniforme azul, convertida en esbirra..." Yoss no mide los peyorativos adjetivos que sirven, en bandeja la irreverencia pusmoderna; de hecho, da voz a los silenciados comentarios que por décadas han circulado en la cultura y el folklore cubano. Pero no todo fue fácil. Los "varones" condescendientes le hacían la vida insoportable porque ocupaba ella un puesto que les correspondía a ellos, a los machos. Pero lo aguantó todo, incluso al "mayor Cevedo, el jefe de la Unidad, que aprovechaba cada ocasión para echarme encima su vaho a tabaco barato y ron peleón"; soportó "la prepotencia cortés e hinchada de testosterona del sargento Triana, el instructor de Combate Cuerpo a Cuerpo"; sobrevivió “el descarado acoso de Rebeca, la instructora de tiro, una mulatona marimacha cuadrada como un escaparate, capaz de colar una bala de su Makarov por el 
ojo de una aguja a treinta metros de distancia, y empeñada en que yo lo que tenía que probar era el calor de hembra"; incluso se acostumbró a la prepotencia de Luis Carlos, "el mejor oficial investigador de la Unidad, un pelirrojo lleno de granos y feo como él solo" porque "se las sabía todas en la mala vida habanera y las que no se las inventaba". Aguantó, endureció el pellejo, aprendió. Acoso sexual viniendo por todos lados, Eleanor O'Farrill resolvió casos de "prostitución de menores y pornografía", de drogas y tráficos de armas; la ascendieron a Primer Teniente y le "asignaron" un carro, un LADA, tan "viejo como El Morro". Pero entonces, en una redada contra distribuidores de drogas, se tropieza con Michael José Gómez, un "pelúo" con tatuajes pero sin antecedentes penales - una suerte de alter-ego del mismo Yoss. Eleanor descubrió que no fumaba ni bebía, que tocaba la guitarra, y decidió dejar al prepotente Luis Carlos y comenzar a salir con el "peluíto simpaticón". Sus padres se habían marchado a los Estados Unidos y se ganaba la vida "tocando el tres como suplente en el conjunto sonero Salsa Habana" a pesar de un "fanático del metal". Michael se disfrazaba "con una guayabera y un sombrero de yarey para esconder la melena". Era un lector tan ávido como Eleanor y era "pésimo cocinando, pero bueno a la hora de comerse cualquier cosa que cocinara yo... Que ya tiene su mérito". Según Eleanor, el chicho "nunca había contraído la 'fiebre del tigre' esa especie de desesperación aguda por irse del país, a cualquier lugar, adónde sea con tal de que sea Extranjia, que afecta a miles de cubanos". Pero no era perfecto: "tenía un alma mercenaria" y pertenecía a una "generación sin fe, pero que no la perdió, sino que nunca la tuvo", tampoco "creía en nada ni en nadie" y "era capaz de hacer prácticamente cualquier cosa con tal de ganarse unos cucs, unos dólares, unos euros o hasta unos rublos si no había más". Lo peor es que "por más que leyera, nunca le gustó la ciencia ficción" y a cada rato se burlaba:

oye, rubia, una policía leyendo a Bradbury o a Asimov es tan absurda como un capitán de navío boliviano. A ver ¿todo eso de hiperespacio, robots, nanotecnología, ciborgs, túneles transdimensionales y mutaciones te sirve para algo en tu trabajo? ¿No, verdad? ¡Pues ponte a comer cáscaras, que el día que tus jefes se enteren te dan baja médica por psiquiatría, y a ver qué nos hacemos entonces! ¡No te veo sin casita ni carrito, y volviendo a Nuevitas a estas alturas del juego!

Una de esas noches mientras caminaba con Michel, Eleanor O’Farrill comenzó a ver el show de luces, el mismo que vio toda La Habana; en los pocos minutos que duró, llovieron las fotografías; pero era un ALGO "no como un aterrizaje de platillos voladores, ni como explosiones nucleares ni como 'el albor de una nueva era' como dijeron después algunos de esos ufólogos fanáticos medio tostados" (12), sino como "luces raras de muchos colores", que daban la sensación de que "el tiempo fluía más lentamente", produciendo una "ligera incomodidad... casi como en una disco cuando ponen demasiado reggaetón" (12). Después del show La Habana continuaba siendo 
exactamente la misma, con sus barrios gentrificados, sus solares y sus mansiones, los hoteles lujos y los tanqueros y leones.

$\mathrm{Y}$ de pronto el cuento-novela arremete fuertemente contra los mecanismos de (des) información nacionales controlados por el Estado, aunque todos lo vieron e incluso CNN pasó las imágenes, el público en el resto de la isla no se enteró de nada,

gracias a la sana tradición de nuestra prensa escrita, radial y televisiva, de no reportar hechos extraños ni criminales, de fingir siempre que todo está bien y que nada raro ocurre jamás (recuerdo el chiste del fantasma de Napoleón diciéndole a Fidel que si él hubiera tenido un periódico como Granma, nadie se hubiera nunca enterado de que había perdido en Waterloo), probablemente la mayor parte de la población de la ciudad no tuvo acceso a todas las informaciones que llegaron a mis manos como oficial criminalista, ni atinó a formarse un cuadro general como yo sí pude hacerlo. (Expreso 13)

Honestamente, hacía mucho tiempo que yo, como lector y crítico no encontraba en una novela publicada por una institución cubana revolucionaria, un chiste sobre Fidel Castro, pero esto será tema de otro ensayo. A estas alturas sería prudente enumerar entonces algunos de los eventos más significativos que ocurrieron después del show de luces silenciado, ¿como la ciencia ficción misma?, por los medios nacionales cuando, y según Eleonor "la ciencia ficción acababa de meterse de lleno en la vida habanera ... [y] lo insólito había adquirido carta de ciudadanía" cubana (26): "grandes cardúmenes de peces nadando arriba y abajo por el Almendares", famoso por su contaminación (13); un "violador de menores y asesino en serie ... gay de carroza declarado ... se entregó voluntariamente a la policía" (14); "los edificios de toda una acera de Cayo Hueso, en Centrohabana, se desplomaron al unísono. No se reportaron víctimas" (14); "aguaceros torrenciales puntuales como relojes suizos" (15); "las aguas se habían retirado más de doscientos metros del Malecón" (16); "todas las auras tiñosas que suelen posarse y/o sobrevolar el Obelisco de la Plaza de la Revolución parecieron ponerse de acuerdo para descender y congregarse en medio de la explanada, al mediodía" (17); "todos los teléfonos de Ciudad de La Habana (incluidos los públicos y los celulares, para más INRI) sonaron a las 6 y 14 de la mañana" (17); "un insólito géiser de fuego estalló en la céntrica intersección vedadense de Línea y L, arrojando trozos del destrozado pavimento y alzando sus potentes llamas a decenas de metros de altura" (17); "el edificio de Coppelia, de la archifamosa heladería, comenzó a hundirse sobre sí mismo" (36); el edificio del Hotel Habana Libre se estaba derritiendo como si fuera de jalea, (40) ... La lista es extensa. Aunque sí se propuso como causa "un complot de la SINA y la CIA con los disidentes para desestabilizar la capital" (19), esta vez la teoría de la conspiración anticubana no prosperó sobre todo porque uno de los eventos tuvo que ver con "nutridos grupos de inmigrantes ilegales cubanos reportados en Amsterdam, Barcelona y Moscú” (18-19). 
Para Eleanor O'Farrill aquellas oleadas de inmigrantes ilegales "no resultaba novedoso" pues estaba acostumbrada como "todo el mundo" en Cuba a que sus "compatriotas, ansiosos de abandonar el país, recurrieran a los medios más imaginativos y extravagantes ... [desde] el clásico 'quedarse'o desertar escurriéndose en el pandemonio de los aeropuertos internacionales de Shannon, Barajas o Gander, hasta sistemas mucho más arriesgados ... como el de los varios mecánicos de aviación que llegaron a Canadá o Europa como polizones en un jet ... algunos de ellos incluso vivos. Y ni hablar de los balseros" (19-20).

Lo que hacía diferente estos casos de los actuales era que en los anteriores "siempre había un vehículo, un truco, un sistema demostrable, palpable, creíble, por temerario que fuera", es decir, una explicación viable y/o visible. Pero ahora simplemente "APARECIAN", a la misma hora y en el mismo lugar, una vez por semana y siempre en Barcelona, Amsterdam y Moscú.

Eleonor, atando cabos, no lograba encontrar el elusivo cómo: “¿Plaza Cataluña? ¿Sheremetievo? ¿Amstelveen, Delft Station? Al menos tres de aquellos sitios ME SONABAN... Y ahí saltó al fin la liebre ... siempre he sido de esas lectoras obsesivas que cuando no tiene otra cosa a mano se pone a leer lo mismo un cartel que los letreros de una guagua ... ¿Una guagua? Por supuesto; España, Holanda y Rusia habían donado hacía poco unos cuantos autobuses usados para mejorar la siempre crítica situación del transporte público habanero. Y ya estaban circulando por nuestras calles, aunque todavía con sus letreros de origen" (23-24). Aquel "espectáculo de luces de la noche del sábado parecía efectivamente haber aflojado los tornillos y las tuercas de las puertas que comunican las dimensiones. O abierto túneles transespaciales" (26). Como resultado, "de un modo u otro, algunos cubanos, probablemente al principio por pura casualidad, pero luego con toda premeditación, estaban usando aquellos autobuses tan generosamente donados y a los que nadie se había preocupado por cambiarles los carteles, para desaparecer exactamente a medianoche de La Habana y reaparecer en Barcelona, Amsterdam y Moscú" (26).

Sin embargo, aquellas migraciones interdismensionales era "el secreto más público de La Habana" y se sabía de un medio de "transporte directo, instantáneo, sin riesgos, ni tiburones ni lanchas guardafronteras ni Guardacostas, sin aduana ni sed ni hambre en la travesía, sin congelamiento ni falta de aire;" era, como se ha pensado por décadas, la materialización de una de una "carretera de diez pistas Habana-Miami;" sólo que ahora, con estar en una de las "guaguas mágicas el sábado a medianoche" tenías el viaje resuelto (26-27).

Pero las guaguas "teletransportadora" regresaban, vacías, pero regresaban. Durante sus investigaciones, despojada de su uniforme "de esbirra" Eleonor descubrió que los demás chóferes decían que "aquella cabrona guagua estaba embrujada, que ya eran tres sábados seguidos que los chóferes y conductores que salían con ella no regresaban, y 
luego el domingo temprano alguien la reportaba abandonada en medio del recorrido" (28). Le habían colocado crucifijos y un Elegguá en el espejo, hasta una estampita del ojo con la lengua atravesada por el cuchillo, contra el mal de ojo" regresaba con la guagua. "Tú estás loca de remate-dictaminó Michael, entre divertido y preocupado" al escuchar las historias ... Esa gente con la fiebre del tigre, como tú le dices, no lee tanta ciencia ficción como tú y hasta "metes a los extraterrestres con túneles interdimensionales en el potaje" (29-30). Y sentenció:

-Oye, pues si quieren irse ¡que se vayan! Pim pom fuera, abajo la gusanera y que se vaya la escoria, como en el 80 o en el 94, que aquí lo que sobra es gente. Y no es asunto tuyo, a fin de cuentas -se encogió de hombros- ¿No te la pasas siempre diciendo lo bueno que sería que quitaran el permiso de salida, abrieran las fronteras y eso? Burlar la maldita circunstancia del agua por todas partes que decía Piñera. Pues ahí lo tienes. Zin-zala-din, y la magia está hecha. Expreso Habana-Amstelveen, como tú dices. (30)

Y después de la bronca y el sexo requerido para calmar los ánimos terrenales, se pusieron a discutir sobre las canciones prohibidas de Porno para Ricardo y del corto Monte Rouge de Eduardo del Llano que circulaban clandestinamente.

Para bien o para mal, a veces acertada y otras no tanto -como el infeliz intento de Soto de hacer un policiaco soviético en el trópico-, la ciencia ficción cubana del nuevo siglo se nos presenta a través de este cuento-novela como una comprometida no solamente con la producción de lo posible e imaginable, sino también con cuestiones de identidad de género, sexualidad, raza, nación, siempre manteniendo una tensión entre subjetividades y objetividades. De hecho, lo que argumento hasta aquí es que la critica pos-revolucionaria y la ciencia ficción deben ser pensadas como las dos caras de una moneda, o tal vez como un poliedro líquido, de modo que una cara depende y se retroalimenta de la otra, en un mecanismo de feedback polisémico que iré desglosando más adelante. Consideremos que si bien la ciencia ficcion de los sesentas a los ochentas, que aparece como inter-texto en Expreso Habana-Amstelven, pensaba más en lo utópico y lejano, en los mundos que vendrán pero con marcada influencia soviética y norteamericana, la ciencia ficción de los noventas a los 2000 se alejó de las tecnologías euro-céntricas y norteamericanas para activar una crítica centrada en los problemas cotidianos del cubano "de a pie", en las crisis de la vida cotidiana, en la migración a toda costa, en los crímenes no reportados para no alterar a un infantilizado espectador del gran circo nacional. Precisamente convirtiéndola en una "literatura" de compromiso político -y recordemos como nos advertían Foucault, Deleuze, Spivak, lo personal es político-. Sólo como recordatorio mínimo, pensemos por ejemplo en "Los mundos que amo" de Daína Chaviano, aquella foto-novela de anticipación que se convirtió en canónica representante de la ficción de 1980 a la cual se hace referencia en Expreso Habana-Amstelven. Chaviano nos presenta unos extraterrestres "blancos y 
rubios" que llegan a La Habana para revelar a una muchacha (definida como naïve y sin nombre) los secretos de las civilizaciones pre-colombinas que ellos/ellas fundaron. $\mathrm{Y}$ aunque como he argumentado anteriormente en otro ensayo la foto-novela leída contra el grano nos ofrece una crítica sobre cuestiones de género e identidad dentro de los parámetros masculinizantes hegemónicos de la revolución, termina reivindicado los meta-discursos de un comunismo real ya propuesto mucho antes en la narrativa cubana de los sesentas-setentas, pienso en Manuel Cofiño y su novela La última mujer y el próximo combate que a pesar de su título se enfoca en la fabricación de un sujeto masculino revolucionario que mostraba la potencialidad del "hombre-nuevo" para llevar adelante el proyecto comenzado en 1959.

Pero con el derrumbe del Campo Socialista y el arribo del Período Especial, los escritores de ciencia ficción de la llamada "generación Y" -también "generación 00", o como prefiero llamarles/llamarnos "generación Asere"- comenzaron a trasladar sus críticas al patio, a los predios donde se articulaban y se articulan aún sus performaces de la vida diaria; y con esta traslación, que no es más que un regreso inevitable al espacio de lo cotidiano, la ciencia ficción en Cuba se convirtió en un sitio o terreno donde se comenzaron a dirimir las siempre tensas luchas por desmontar los meta-discursos enarbolados en décadas anteriores.

Regresando al personaje de Eleanor O'Farrill, su vida es un viaje por entre las redes del poder, y su posición como miembro del MNINT con auto LADA propio le permite moverse mecánicamente, y por ende articularse como sujeto, siempre cruzando por los intersticios del poder de los cuales no escapan el resto de los sujetos a su alrededor -ni ella tampoco-, quienes han sido codificados a su vez por la narrativa del cuento como el Otro dentro del Nos-Otros (los gay, las jineteas, los pingueros, etc.). Claro, a no ser tomen una de las guaguas mágicas y puf, (des)aparezcan en otro continente.

\section{NómADAS, ILEGALES Y OTROS NOMBRETES}

La ciencia ficción como género se articula entonces como mediadora o interface discursiva entre la trayectoria del personaje de ficción y Eleanor-nómada cuya trayectoria se extiende de los ensamblajes macro a los micro. Pero aún más atractivo resulta pensar que aquí la ciencia ficción misma se mueve de ser herramienta a ser arma con interesante simplicidad; o como sugieren Deleuze y Guattari, la ciencia ficción en este caso se coloca como herramienta en la trama pues es abstractamente mucho más rápida que el arma, la cual es más "opresiva" o pesada (398). De ésta manera, la herramienta-ciencia ficción "is essentially tied to a genesis, a displacement, and an expenditure of force whose laws reside in work", mientras que "the weapon concerns only the exercise or manifestation of force in space and time, in conformity with free action" (398). La ciencia ficción es en este cuento-novela de Yoos lo que suplementa realmente la trayectoria del sujeto nomádico, en un proceso constante de deterritorialización, deviniendo constantemente 
otra que no es ella misma (la escena en el espejo por ejemplo, donde ella se ve realmente quien es pero quiere ser otra).

De cierta manera en el cuento Eleanor no solamente se puede interpretar como sujeto nomádico que derriba barreras, sino también como componente central de lo que Deleuze y Guattari concibieron como "la máquina de guerra" (the war machine). Ella es, tácitamente, miembro de los “órganos” represivos del Estado cubano, del MININT, el centro de inteligencia y monitoreo de la población; lo cual es sumamente interesante si consideramos, como he sugerido arriba, que ella puede leerse también como sujeto nomádico.

Desglosando las ideas, ella es parte de una compleja máquina a la cual debe su educación pero también su desarrollo como sujeto (femenino); de hecho, su integración al MININT tiene más que ver con sus traumas infantiles y los abusos físicos de sus vecinitas y verbales de su madre, que con políticas afectivas ideológicas. Es decir, en su caso, el Estado ha facilitado su experiencia nomádica pero ha creado o quizás ignorado sus propiedades autónomas y clandestinas, lo cual puede leerse como típificante de las interacciones entre el estado y lo nómada si seguimos a Deleuze y Guattari. Eleanor trabaja para el estado, pero a su vez actúa contra el mismo, a través de su intereses casi clandestinos por la ciencia ficción -una ciencia ficción extranjera, en inglés, norteamericana con vestigios de soviética-. Si bien la revolución, y las políticas educacionales de los años sesentas, crearon un sujeto "letrado" a lo Rama, estos mismos sujetos son quienes ahora retan no tan veladamente las estructuras hegemónicas y de censura de esa revolución que los modeló como futuros-posibles.

Regresando, para concluir a la cuentinovela Expreso Habana-Amstelven, aunque no del todo, poco a poco, los efectos de aquellos insólitos fenómenos que habían trastornado a La Habana y a sus habitantes durante las últimas 48 horas fueron revertiendo (41). A Michel le negaron la visa para salir del país con su grupito de música tradicional y decidió salir a buscar el Expreso Habana-Amstelven (46). Eleonor lo supo en una carta que dejó su "cyborg replicante viajero del tiempo mutante favorito" aquella noche de sábado; la carta concluía exaltándola como la mejor policía, como el amor de su vida, y prometiendo regresar cargado de "pacotillas incluyendo pañales desechables, claro" (43).

Pero ya en ese momento ella había encontrado la solución revolucionaria a la (e/ in)migración ilegal que estaba causando problemas internacionales: con sólo cambiar una letra en los carteles de destino, interrumpiría el flujo, cambiaría el futuro en el presente: "el Expreso Habana-Amstelveen ... lo había dejado en Habana-Amstelven", quitando una "e" pero antes de la crítica hora de la medianoche del sábado (43). Aún así, Michel nunca regresó.

Eleanor O’Farrill, acogiéndose a la licencia de maternidad, dejó de trabajar y había decido escribir esta historia: "una se aburre tanto, solita en casa, sin nada que hacer ... desde aquella noche final de locura no han vuelto a aparecer más cubanos en Amsterdam, Moscú ni Barcelona" (44). 
Pero conociendo a sus coterráneos, Eleanor O’Farrill no duda que un día, en un futuro no lejando, aparezca en los diccionarios la siguiente definición:

Cubano (pl, cubanos): Adjetivo, gentilicio. Oriundo de Cuba (país mítico hasta ahora no localizado en el sistema de coordenadas espacio temporales) -Los cubanos, pueblo nómada de dudoso y discutido origen, llegaron hace unos años a varias localidades del Multiverso Metagaláctico, de manera inesperada y por medios desconocidos. Pese a sus diferentes aspectos étnicos, todos afirman proceder de la misma nación: una legendaria isla (Cuba) situada en medio de un mar llamado Caribe. (Expreso 45; énfasis mío)

Al final de la historia, Eleanor es un híbrido que trabaja para el poder (hegemónico, del estado) y con la resistencia a ese poder, operando dentro de los márgenes entre lo público y lo privado, lo macro y lo micro, la ciudad y las periferias. Pero además, ella como nómada establece una nueva estructura dual cuando se articula, a través de la narración de su propia trayectoria como sujeto deviniendo-revolucionario, como dentro de las estructuras del discurso intelectual y cultural -ese que aún considera la ciencia ficción como género menor- y el contra-discurso que propone la ciencia ficción del nuevo milenio. Pero hay más, este cuento-novela de Yoss propone que la máquina revolucionaria existe porque el/la nómada existe a su vez, y la reconfigura -a la máquina misma- en su trayectoria cotidiana como sujeto con capacidad de acción socio-política (Delueze y Guattari). La moneda y sus dos caras, Janus tropical. Eleanor-nómada se opone al estado y lucha contra las estereotípicas ideas que desvalorizan la ciencia ficción, especialmente las de su novio, el cual se comporta tal y como lo hizo el chico de "Los mundos que amo" de Daína Chaviano en la foto-novela de los años ochenta, como un machito ignorante que considera TODA la ciencia ficción como cosa de geeks y nerds, como ficción inconsecuente, o como quizás en la cita que comenté al comienzo, como mecanismo de enajenación política.

Es interesante porque el sujeto masculino contraparte de Eleanor, aunque no pertenece como ella a las estructura represiva estatal, termina revalidando las normas culturales impuestas por los aparatos administrativos de la cultura revolucionaria cubana a lo largo de más de cinco décadas. Pero en este cuento-novela de Yoss no es suficiente la guerra contra la máquina, al final los cubanos seguirán emigrando at infinitum; lo importante para Yoss es crear líneas de vuelo, la constitución de un espacio liso y subrayar el movimiento de las personas en el espacio de un estado-nación con fronteras trans-dimensionales. Avanzar fuerzas de resistencia es lo que propone el cuento-novela, pero a través de la ciencia ficción como extrapolación a la creación pos-revolucionara, "pus-moderna", irreverente en bandeja o en guagua mágica.

Textos como este, aunque no pretendo haberle hecho total justicia, realmente nos conminan a generar un crítica y un cuerpo teórico que se mueva tan rápido como el género de la ciencia ficción en sí mismo, un género que está en flujo constante y muchas 
veces, como lamentaba Grillo, se adelanta a los críticos en términos de sus exploraciones éticas y socio-políticas. ¡Veinte CUCs bien gastados!

\section{BiBLIOGRAFÍA}

Acosta, Reinaldo. “Crónicas de lo ajeno y los lejano”. La Habana: Letras Cubanas, 2010. Arango, Arturo. "Con tantos palos que te dio la vida: poesía, censura y persistencia". Ensayo leído como parte del ciclo "La política cultural del período revolucionario: Memoria y reflexión”. La Habana, mayo 2007.

Deleuze y Guattari. A Thousand Plateaus. Minneapolis: U of Minnesota P, 1987. 230-50. Fabry, Geneviève y Claudio Canaparo, eds. El enigma de lo real: las fronteras del realismo en la narrativa del siglo XX. Oxford: Peter Lang, 2007.

García Acosta, Félix (Felo). "La narrativa cubana en el siglo XXI: entrevista a Rafael Grillo". Isliada. La Habana, 28 de junio de 2011.

González Neira, Fabricio. "Ciencia ficción cubana: problemática y supervivencia". Disparo en Red (2000).

Guanche, Julio César. "El camino de las definiciones. Los intelectuales y la política en Cuba. 1959-1961". Temas 45 (2006): 106-113.

Hollinger, Veronica y Joan Gordon, eds. Edging into the Future: Science Fiction and Contemporary Cultural Transformation. Philadelphia: U of Pennsylvania P, 2002. 1-8.

López Sacha, Francisco. Literatura cubana y fin de siglo. Editorial Poetas Antiimperialistas de América <http://www.lahaine.org>. 14 oct. 2002.

Mourdoch, Dennis. "Las dos caras”. Isliada. La Habana, 28 noviembre 2012.

Noroña, Juan Pablo. "Resumen de las etapas editoriales del fantástico cubano". Korad 10: Revista digital de literatura fantástica y de ciencia ficción. Ciudad de La Habana, Cuba. Julio-Septiembre, 2012.

Pearson, Wendy G., Veronica Hollingery Joan Gordon, eds. “Queer Universes: Sexualities in Science Fiction.” Liverpool: Liverpool UP, 2008.

Reloba Santana, Juan Carlos. "Cuentos cubanos de ciencia ficción" (introducción). La Habana: Gente Nueva, 1983. 5-7.

Román, N.V. Universo de la ciencia ficción cubana. La Habana, Cuba: Ediciones Extramuros (2005).

Yoss (José Miguel Sánchez Gómez). "La guayaban mecánica: Antología histórica de la ciencia ficción cubana”. Milán: Universitá de Milano, 2004. 3-11.

Expreso Habana-Amstelven. La Habana: Isliada Editores, 2013.

"Marcianos en el platanal de Bartolo: Análisis de la historia y perspectivas de la ciencia ficción en Cuba". Cuba Literaria. 25 mayo 2005. <http://www.cubaliteraria. cu/articulo.php?idarticulo $=11151 \&$ idseccion $=33>$. 